\title{
The Internet will be How to Change the Landscape Industry
}

\author{
Baiyi $\mathrm{An}^{1, \mathrm{a}}$ and Wei Shen ${ }^{2, \mathrm{~b}^{*}}$ \\ ${ }^{1}$ College of Horticulture,Jilin Agricultural University,Jilin, China \\ ${ }^{2}$ College of Computer Science and Technology,Beihua University,Jilin, China \\ aswabyswaby@163.com, babyswabysw@163.com
}

Keywords: Internet; Data; Nursery stock industry; Information

\begin{abstract}
China's Internet development to what extent? Each of us feel the Internet rapidly, mind not intuitive proof data. Let Numbers to tell you about China's Internet development present situation. On the way of the Internet, landscape nursery stock industry already behind other people's livelihood industry a big step, but the possibility of future development is still have a lot of other industries in the process of the development of the Internet to do try also can provide some thinking for garden industry. Change the direction of the industry can also be reassuring.
\end{abstract}

\section{Introduction}

China's Internet development to what extent [1]? Each of us feel the Internet rapidly, mind not intuitive proof data. Let Numbers to tell you about China's Internet development present situation [2].

On the way of the Internet, landscape nursery stock industry already behind other people's livelihood industry a big step [3], but the possibility of future development is still have a lot of other industries in the process of the development of the Internet to do try also can provide some thinking for garden industry. Change the direction of the industry can also be reassuring [4].

\section{Current Situation of the Development of China's Internet}

According to the China Internet network information center for the China Internet network development state statistic report, you can see as of June 2015, 668 million Internet users in China. Only at the end of 2014 to June 2015, 18.94 million Internet users were created half a year's time. Internet penetration rate was $48.8 \%$, and the social various aspects influenced by the network of the people's livelihood $[5,6]$.

At the same time, mobile phones beyond computers become the first big Chinese Internet users surfing the Internet terminals.594 million mobile Internet users in China, is an increase of 36.79 million in December 2014, the use of mobile Internet ratio 20.5\% more than a PC. Internet users in the use of mobile Internet population accounted for up to $88.9 \%$, with the bigger of mobile terminals and the improving of the mobile application experience, as users main Internet terminal further clear trend.

Figures show that China's rural 186 million Internet users, an increase of 8 million compared with the end of 2014.The urban areas and rural areas of Internet penetration rate were $64.2 \%$ and $30.1 \%$ respectively, a difference of $34.1 \%$.Rural area 10 to 40 people aged Internet penetration of $15-27 \%$ lower than the urban areas $[7,8]$.

According to statistics, at present China's fixed width to the port number of 407 million[9], covers all cities in China, villages and towns and $93.5 \%$ of administrative villages. A fixed number of broadband users more than 200 million households, broadband scale in the world's first. Mobile broadband users ( $3 \mathrm{~g} / 4 \mathrm{~g}$ ) accumulative total of 674 million units, public and home Wi-Fi, becoming increasingly prevalent in the network environment, WLAN public access point (AP) a total of 6.045 million. And in the push of economic, China's Internet contribution rate to economic growth significantly promoted, the world first. Internet economy accounted for in GDP continued to rise, to $7 \%$ in $2014[10]$. 


\section{The Nursery Stock Industry and Combining the Current Situation of the Internet}

Further deepen the influence of the Internet for personal lifestyle, from entertainment information acquisition and communication based on the needs of personalized applications, development and health care, education, transportation and other public service depth fusion of the livelihood of the people. Garden industry, of course, also be to promote continuous development of the Internet to upgrade [11,12], but relative to people's livelihood service industry, landscape industry and Internet application is still in its infancy.

Around 2000, garden industry from the earliest paper media industry transformation from the Internet [13].The first generation of garden is Internet portal, ruled by social era, the core business model for the flow to liquidate, mainly to the enterprise to provide a display platform and information exchange platform. In the Internet originally applied to various industries development pattern, landscape industry did not lag behind the other industries. But today, Internet + , after be brought up the concept of Internet course industrial transformation and upgrading of development [15], have turned to other industries. But garden industry is still at the primary stage of development of the Internet. Did not realize the online trade, supply and demand both sides did not form a substantial interaction, the two sides is still in unilateral release information with the traditional way to trade.

\section{The Nursery Stock Industry Change}

In recent years, countries have been promoting the green, green city in China, the concept of green countryside, go "let city embraced forest, forest to encircle the cities" development train of thought.

Building a green China, is a development mode, system engineering, consumption idea and way of life change in the future will develop the green industry, optimize the industrial structure, eliminate excess capacity, promote industrial structure change "light", the development mode change "green", economic quality "optimal"; At the same time promote green consumption trend of the whole society.

Countries to support green industry is gradually enhanced, this also requires garden industry to seize the opportunity to complete nirvana. In this context, the Internet under the embrace of landscape nursery stock industry, there will be what kind of change [16]?

1. A comprehensive Internet. Based on large data, the two sides of supply and demand information is transparent, in the shortest possible time to build trust [17].

2. Nursery stock products will be more and more similar characteristics, and has a better user experience of product will stand out[18].The precision of Internet information service development, will promote the process of pursuing higher quality nursery stock industry.

3. Online and offline will combine, form more specification of the specifications of the perfect system and price system. Return to rational market [19], unreasonable profits will be squeezed.

4. The excavation of large data, generate guidance nursery seedling index model of production, management and development. Change of seedling trading mode [20], search mode, mode of production and management mode, the industry gradually shift from the traditional artificial intelligence.

5. Cancel the intermediate links, procurement upstream and downstream suppliers directly face to face. From the blind competition to multiple cooperation. Directly to the customer, more personalized and customized [21].

6 . Internet + seedlings would promote seedling enterprise brand, encourage enterprises to carry out high quality products and prestige [22].

7. For the standard of the landscape plants online [23], will make more close to the financial, nursery stock industry production and port will also usher in a better mode of an open ground.

8. Via the Internet to establish credit mechanism to determine nursery industry's evolution. The construction of credit system will be more sunshine [24], more peer-to-peer dialogue at the ends of the supply and demand. 


\section{Nursery Stock Industry Development in the Future}

Landscape Architecture Market Capitalization Gradually Toward The Society. Construction of landscape architecture in urban construction, ecological construction, spiritual civilization, and the national economic and social development of overall importance, basic and pilot, is obviously a Shared public welfare undertakings.At present, the capital of landscaping industry is the main source of government investment is given priority to, private capital and social capital injection is complementary[25,26].

Across the developed world garden green industry capital market, capital market is actively involved in the whole society. Landscape industry development in our country in the future, will be under the premise that the government guidance, multi-channel [27], diversified development mode, mainly to participate in a variety of economic elements, attract a large number of private capital and foreign investment in landscape construction, landscape architecture construction.

Garden Planning Design Concept Extension, Towards the Diversified Design. Compared with the past more than ten years, the types of landscape architecture planning and design projects, the depth and breadth have been greatly expanded and are turned away from traditional garden design in modern landscape planning and design.

The future development of landscape design, on the basis of traditional theory, aesthetic theory, function theory, landscaping theory, the theory of garden city, leisure recreation theory, theory of green space structure, etc.), absorption of environmental ethics, environmental psychology and new concepts such as ecological philosophy, will be people-oriented[28], to the person and nature coordination as the goal, gradually to the ecological design, culture, regional design, the combination of science and art design.

"Ecological City" is the Development Trend of Contemporary Urban Landscape Construction. For decades, the discussion of "ecological city", the deepening of environmental awareness, make people understanding of landscape in the position in the city have further sublimation. With the development of science[29], the progress of the society and the improvement of people's living standards, has the development of the urban landscaping and level height to know to protect the ecological balance.

Ecological garden is to maintain ecological balance, and beautify the environment as the dominant idea, advocated adjust measures to local conditions, suitable for, follow the ecology principle. The main body of ecological garden is the natural biological communities or simulated natural biological community, emphasizes the combination of artificial landscape and the natural biological communities[30].

Urban garden is based on artificial ecosystem as the main body of landscape, such as urban comprehensive park, zoo, botanical garden, small garden, the street green space and so on.Urban landscape become an important part of urban construction, become the important symbol of modern city, the importance of urban landscaping in urban construction are increasingly significant, implementing urban landscape ecology has become the inevitable trend of world city landscape development.

\section{Conclusion}

Under the new ecological, traditional industry more or less.But whether to use the Internet business model innovation, or to transform traditional industries, to comply with the laws of the Internet itself development and operation, and reasonable use of its resources and potential.Achieve the perfect combination of "harmony", is much-anticipated garden Internet mode.

\section{Acknowledgement}

The authors wish to thank the Education Department of Jilin Province [2015](127th) and [2015](182nd),Jilin science and Technology Bureau(201467006),Science and Technology 
Department of Jilin Province (20150204045NY), Jilin Province Education Science Planning Project (GH14126）、（GH14127） under which the present work was possible.

\section{References}

[1] D'haeseleer P, Liang S, Somogyi R. Genetic network inference: from co-expression clustering to reverse engineering[J]. Bioinformatics 2000, 16: 707-726.

[2] Dojer N, Gambin A, Mizera A, et al. Applying dynamic Bayesian networks to perturbed gene expression data[J]. BMC Bioinformatics, 2006, 7: 249.

[3] Beal M J, Falciani F, Ghahramani Z, et al. A Bayesian approach to reconstructing genetic regulatory networks with hidden factors[J]. Bioinformatics, 2005, 21: 349-356.

[4] Bansal M, Gatta G D, di Bernardo D. Inference of gene regulatory networks and compound mode of action from time course gene expression profiles[J]. Bioinformatics, 2006, 22: 815-822.

[5] Eugene N, Emmanuel B. Regulatory network reconstruction using an integral additive model with flexible kernel functions[J]. BMC Systems Biology, 2008, 2: 8.

[6] Nelson P A, Kahana Y. Spherical harmonics, singular-value decomposition and the head-related transfer function[J]. Journal of Sound and Vibration, 2001, 239(4): 607-638.

[7] Liang M L, Dai L F. The left and right inverse eigenvalue problems of generalized reflexive and anti-reflexive matrices[J]. Journal of Computational and Applied Mathematics, 2010, 234: 743-749.

[8] Brits R, Engelbrecht A P, van den Bergh F. Locating multiple optima using particle swarm optimization[J]. Appl Math Comput, 2007, 189(2): 1859-1883.

[9] Chen D Y, Chuang T R, Tsai S C. Jgap: A java-based graph algorithms platform[J]. Software Pract Exper, 2001, 31(7): 615-635.

[10] Tim F R, Philippe R S, Paul T S, et al. A simple spreadsheet-based, MIAME-supportive format for microarray data: MAGE-TAB[J]. BMC Bioinformatics, 2006, 7: 489.

[11] Bansal M, Belcastro V, Ambesi-Impiombato A, et al. How to infer gene networks from expression profiles[J]. Mol Sys Biol, 2007, 3: 78.

[12] Barabási A L, Albert R. Emergence of scaling in random networks[J]. Science, 1999, 286: 509-512.

[13] Silva A C, da Silva J K L, Mendes J F F. Scale-free network with Boolean dynamics as a function of connectivity[J]. Phys Rev E, 2004, 70(6): 66140-66147.

[14] Wilhite S E, Barrett T. Strategies to explore functional genomics data sets in IVCBI's GEO database[J]. Methods Mol Biol, 2012, 802: 41-53.

[15]KEGG Cell cycle-yeast-Saccharomyces cerevisiae[EB/OL]. [2010-04-13].http://www.genome.jp/kegg/pathway/sce/sce04111.html

[16] Wang Z, Shaik S, Inuzuka H, et al. Systems Biology Approaches in Breast Cancer Studies. in Breast Cancer Metastasis and Drug Resistance. Ahmad AEd.: Springer New York, 2013. pp. 329-340.

[17] Penfold C A, Wild D L. How to infer gene networks from expression profiles,revisited. Interface Focus. 2011, 1(6). 857-870. 
[18] Hurley D, Araki H, Tamada Y, et al. Gene network inference and visualization tools for biologists: application to new human transcriptome datasets. Nucleic Acids Research. 2012, 40(6). 2377-2398.

[19] Kiiveri H, de Hoog F. Fitting very large sparse Gaussian graphical models.Computational Statistics \& Data Analysis. 2012, 56(9). 2626-2636.

[20] Vignes M, Vandel J, Allouche D, et al. Gene Regulatory Network Reconstruction Using Bayesian Networks, the Dantzig Selector, the Lasso and Their Meta-Analysis. PLoS ONE. 2011, 6(12). e29165.

[21]Zhang F, Kaufman H, Deng Y, et al. Recursive SVM biomarker selection for early detection of breast cancer in peripheral blood. BMC Medical Genomics.2013, 6(Suppl 1). S4.

[22] Grzegorczyk M, Husmeier D. Improvements in the reconstruction of time-varying gene regulatory networks: dynamic programming and regularization by information sharing among genes. Bioinformatics. 2011, 27(5).693-699.

[23] Del Genio C I, Kim H, Toroczkai Z, et al. Efficient and Exact Sampling of Simple Graphs with Given Arbitrary Degree Sequence. PLoS ONE. 2010, 5(4).e10012.

[24] Netrapalli P, Banerjee S, Sanghavi S, et al. Greedy learning of Markov network structure. In Communication, Control, and Computing (Allerton), 2010 48th Annual Allerton Conference on, 2010, pp. 1295-1302.

[25] Villaverde A, Ross J, Banga J. Reverse Engineering Cellular Networks with Information Theoretic Methods. Cells. 2013, 2(2). 306-329.

[26] Zhang X, Zhao X-M, He K, et al. Inferring gene regulatory networks from gene expression data by path consistency algorithm based on conditional mutual information. Bioinformatics. 2012, 28(1). 98-104.

[27] Huynh-Thu V A, Irrthum A, Wehenkel L, et al. Inferring Regulatory Networks from Expression Data Using Tree-Based Methods. PLoS ONE. 2010, 5(9).e12776.

[28] Saksena G, Mermel C, Getz G. Developing Algorithms to Discover Novel Cancer Genes: A look at the challenges and approaches. Signal Processing Magazine, IEEE. 2012, 29(1). 89-97.

[29] Bo Yang, Junying Zhang, Yaling Yin, and Yuanyuan Zhang. Network-Based Inference Framework for Identifying Cancer Genes from Gene Expression Data. BioMed Research International. 2013, 13(9), Article ID 401649, 12 pages.doi:10.1155/2013/401649.

[30] Jiao Y, Lawler K, Patel G S, et al. DART: Denoising Algorithm based on Relevance network Topology improves molecular pathway activity inference. BMC Bioinformatics. 2011, 12. 